\title{
From Nanometer to Atomic Resolution X-ray EDS analysis of Al in Ni-rich Layered Oxide Li-Ion Cathodes
}

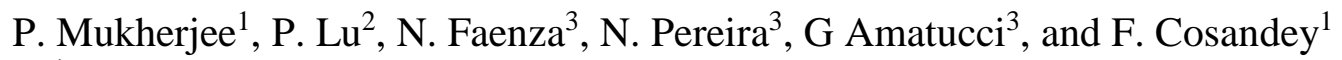 \\ ${ }^{1}$ Department of Materials Science \& Engineering, Rutgers University, Piscataway, NJ 08854 \\ ${ }^{2}$ Sandia National Laboratories, Albuquerque, NM 87185. \\ ${ }^{3}$ Energy Storage Research Group, Rutgers University, North Brunswick, NJ 08902.
}

Ni-rich $\mathrm{LiNi}_{0.8} \mathrm{Co}_{0.15} \mathrm{Al}_{0.05} \mathrm{O}_{2}$, commonly known as $\mathrm{NCA}$, is one of the highest capacity cathode materials currently being used commercially. Although for safety reasons, the commercial use of the NCA cathodes is limited to $3.8 \mathrm{~V}$, but its relative stability at high charge voltage makes it a promising candidate for high capacity Li-ion batteries [1]. This structural stability of NCA at high voltage is unlike its parent compounds $\mathrm{LiNiO}_{2}$ and $\mathrm{LiCoO}_{2}$, both of which degrade rapidly at high voltages (usually > $4.5 \mathrm{~V})$. It has long been argued that Al plays a critical role in structural stability of NCA, but the exact manner in which Al stabilizes the structure is not known yet. A quantitative determination of the distribution of $\mathrm{Al}$ in cathodes held at high voltages, both at the surface and inside the particle, is key to understand the role it plays. Although the segregation behavior of $\mathrm{Al}$ [2] in high 50\% $\mathrm{Al}$ content LNA has been studied quantitatively, its behavior at low Al content and at state of charge is at present unknown. The low concentration of $\mathrm{Al}$ in NCA makes quantitative analysis difficult. In this work, we are studying the distribution of Al by X-ray energy-dispersive spectroscopy (EDS) at both nanometer and atomic levels in a series of compounds starting with $\mathrm{LiAlO}_{2}$ (LAO), $\mathrm{LiNi}_{0.8} \mathrm{Al}_{0.2} \mathrm{O}_{2}$ (LNA), and $\mathrm{LiNi}_{0.8} \mathrm{Co}_{0.15} \mathrm{Al}_{0.05} \mathrm{O}_{2}$ (NCA). This study includes pristine condition as well as electrochemically stressed at a high voltage of $4.75 \mathrm{~V}$ with $\mathrm{LiPF}_{6}$ and $\mathrm{LiBF}_{4}$ electrolytes.

Nanometer resolution X-ray EDS mapping and STEM imaging were performed at Brookhaven National Laboratory in a FEI Talos ${ }^{\mathrm{TM}}$ microscope. Atomic resolution EDS measurements were performed in a FEI Titan ${ }^{\text {TM }}$ G2 80-200 STEM with a Cs probe corrector at Sandia National Laboratories. Both microscopes were fitted with four super EDS Bruker detectors.

The $\mathrm{Al}$ composition as a function of distance from the edge of the particle is shown in Figure 1 for (a) pristine NCA and for electrochemically stressed NCA at $4.75 \mathrm{~V}$ and $60^{\circ} \mathrm{C}$ for $10 \mathrm{hrs}$ with (b) $\mathrm{LiPF}_{6}$ and (c) $\mathrm{LiBF}_{4}$ electrolytes. In all cases there is $\mathrm{Al}$ enrichment at the surface. For pristine NCA the $\mathrm{Al}$ enrichment decreases to an $\mathrm{Al}$ composition about $4.5 \%$ below the surface. However, at $4.75 \mathrm{~V}$, the $\mathrm{Al}$ composition decreases to 2.5 and 3 at\% $\mathrm{Al}$ for $\mathrm{LiPF}_{6}$ and $\mathrm{LiBF}_{4}$ respectively. So, under chemically stressed conditions, some $\mathrm{Al}$ has dissolved from the electrode. This kind of preferential distribution of $\mathrm{Al}$ is also observed in pristine $\mathrm{LiNi}_{0.8} \mathrm{Al}_{0.2} \mathrm{O}_{2}$ (Figure 1d). The $\mathrm{Al}$ is distributed preferentially at the corners and some facets of the particle. The core of the particle remains essentially Al deficient. The atomic resolution HAADF STEM image of one such particle is shown in Figure 2a. The layered LNA compound is electron beam sensitive and in order to obtain sufficient X-ray counts for obtaining atomic resolution EDS maps, a summation of all unit cell within the map has been performed as described previously [3]. The averaged HAADF STEM image is shown in Figure $2 b$ with the corresponding atomic-scale EDS maps for (c) O-K, (d) Ni-K and (e) Al-K. It can be seen that $\mathrm{Ni}$ and $\mathrm{Al}$ occupy the same octahedral sites. The X-ray intensity profiles for $\mathrm{Ni}$ and $\mathrm{Al}$ are shown in Figure $2 \mathrm{f}$. For $\mathrm{Ni}$, the intensity profile is sharp while some broadening in the Al position is observed which could be due to smaller Al-O distance for some $\mathrm{Al}$ positions as compared to Ni-O distance. After the second EDS map from the same region, some $\mathrm{Ni}$ atoms have migrated (induced by the electron beam) to the Li layer position as revealed by the small peak between the $\mathrm{Ni}$ positions. Further work is in progress to 
determine in more details the Al positions in LNA and to determine by EELS the chemical state of Al in the same area of the particles [4].

[1] Sallis S.et.al. Applied Physics Letters 2016, 108, 263902.

[2] Croguennec L., et.al, Chem. Mater. 2009, 21, 1051-1059.

[3] Lu, P. et.al, Nano Lett. 2016, 16, 2728-2733.

[4] The funding for this work is provided by NECCESS, an Energy Frontier Research Center funded by the U.S. Department of Energy, Office of Science, Office of Basic Energy Sciences under Award Number DE-SC0001294. This research used resources of the Center for Functional Nanomaterials, which is a U.S. DOE Office of Science Facility, at Brookhaven National Laboratory under Contract No. DE-SC0012704. Sandia National Laboratories is a multi-program laboratory managed and operated by Sandia Corporation, a wholly owned subsidiary of Lockheed Martin Corporation, for the US Department of Energy's National Nuclear Security Administration under contract DE-AC0494AL85000.

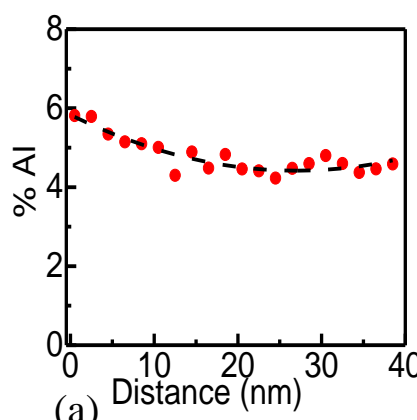

(a)

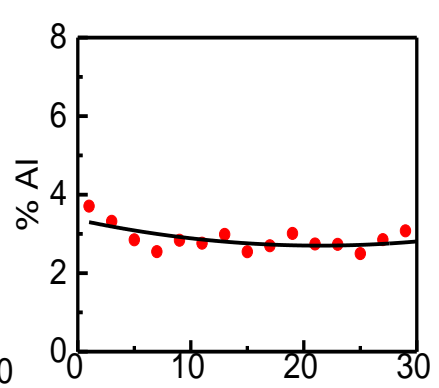

(b) Distance $(\mathrm{nm})$

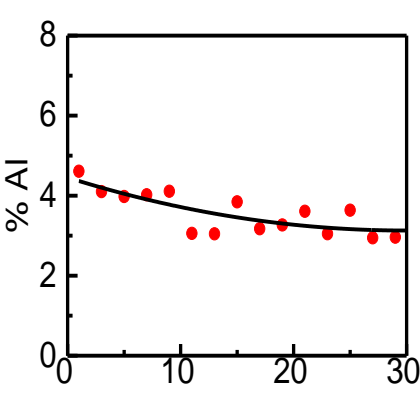

(c) Distance $(\mathrm{nm})$

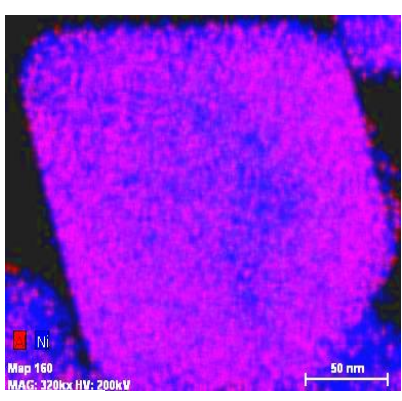

(d)

Figure 1. (a-c) Variation of Al content in NCA as a function of distance from the edge of (a) NCA pristine, (b) NCA held for $10 \mathrm{hrs}$ at $4.75 \mathrm{~V}$ in $\mathrm{LiPF}_{6}$ electrolyte and (c) NCA held for 10 hrs at $4.75 \mathrm{~V}$ in $\mathrm{LiBF}_{4}$ electrolyte. (d) Quantitative X-ray EDS map in pristine LNA showing $\mathrm{Al}$ enrichment at the surface. (Red represents $\mathrm{Al}$ and blue represents $\mathrm{Ni}$ )

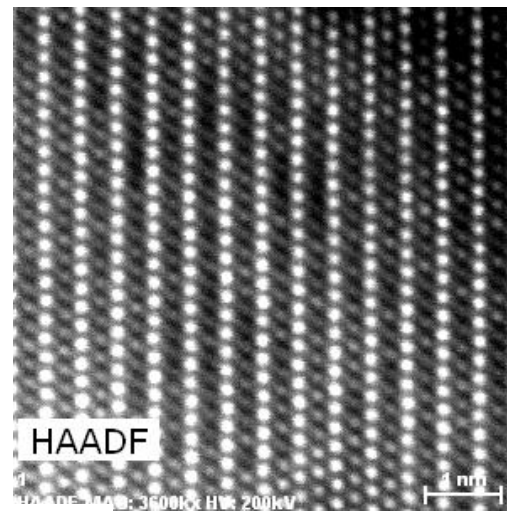

(a)

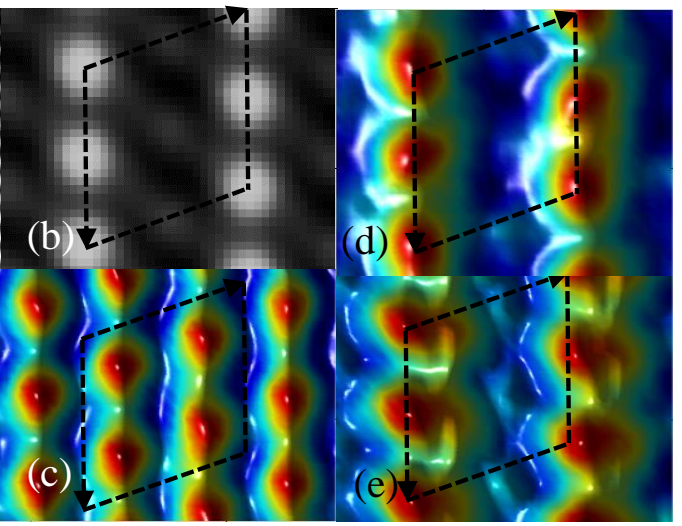

Figure 2. (a) HAADF-STEM image of LNA with (b) unit cell averaged STEM image and corresponding atomic resolution X-ray EDS maps of (c) O-K, (d) Ni-K and (e) Al-K and in (f) the intensity profile of $\mathrm{Ni}-\mathrm{K}$ and $\mathrm{Al}-\mathrm{K}$ after first and second scan map 